\title{
Uma revisão bibliográfica integrativa referente à primeira etapa da proposta de pesquisa sobre o desenvolvimento de produtos do color e trim para o interior de aeronaves
}

An integrative bibliographic review on the first stage of the proposal

for development of color and trim products into aircraft design

\author{
Erika Yamamoto Lee \\ Universidade Federal do Paraná \\ erikaylee@gmail.com
}

Viviane Gaspar Ribas El Marghani

Universidade Federal do Paraná

viviane.elmarghani@gmail.com

PROJËTICA

\section{COMO CITAR ESTE ARTIGO:}

LEE, Erika Yamamoto; EL MARGHANI, Viviane Gaspar Ribas. Uma revisão bibliográfica integrativa r eferente à p rimeira e tapa da p roposta d e pesquisa sobre o desenvolvimento de produtos do color e trim para o interior de aeronaves. Projética, Londrina, v. 12, n. 1, p. 39-66, 2021.

DOI: 10.5433/2236-2207.2021v12n1p39

Submissão: 15-08-2017

Aceite: $29-10-2019$ 
Projética, Londrina, v. 12, n. 1, p. 39-66, março 2021

RESUMO: O artigo apresenta a aplicação da Revisão Bibliográfica Integrativa (RBI), um método sistemático, rigoroso, o qual possibilita ao pesquisador realizar decisões precisas, pois obtém o estado da arte sobre o assunto abordado, assim como a acurada apresentação das lacunas de pesquisa. Tal método de pesquisa é utilizado nos estudos de áreas da saúde, educação, informática e pouco aplicado em pesquisas no Design. Aqui, a RBI foi adotada para o desenvolvimento do capítulo de revisão bibliográfica de uma tese de doutorado na área do Design, que busca pesquisar estudos sobre o tema color e trim no design de interiores de aeronaves. O resultado apresenta todo o procedimento da RBI utilizado em temas do processo no design de interiores da aeronave, pois é um setor que exige do pesquisador uma busca do alto rigor técnico e científico, para o desenvolvimento de novas soluções. Na aplicação da RBI para esta pesquisa, resultaram doze artigos e dezenove teses relevantes.

Palavras-chave: Revisão bibliográfica integrativa. Pesquisa metodológica em Design. Engenharia Kansei. Color trim e interior de aeronaves.

ABSTRACT: This paper presents the application of the Integrative Literature Review (ILR) in Product Design. The ILR is a systematic, rigorous method, which allows the researcher to make accurate decisions, as it captures the state-of-art of the subject, as well as a presentation of the research gaps with precision. The method is innovative and has been used for studies in the fields of health, education, and cutting-edge technology. The ILR was applied in the literature review chapter of a doctoral thesis in the field of product design, which seeks to research studies on the color and trim in aircraft interior design. The present results encompass all ILR procedures applied in subjects of the aircraft interior design process, for it is a field that requires from the researcher a high technical and scientific rigor to the development of new solutions. The application of the ILR for this research retrieved twelve relevant articles and nineteen theses.

Keywords: Integrative Literature Review. Design research methodology. Kansei engineering. Color trim and aircraft interior. 


\section{Uma revisão bibliográfica integrativa... interior de aeronaves}

LEE, Erika Yamamoto; EL MARGHANI, Viviane Gaspar Ribas

\section{INTRODUÇÃO}

A pesquisa na área do Design é crescente, pela variabilidade e interdisciplinaridade entre as áreas que buscam alcançar soluções eficazes para a resolução de problemas. A exclusividade dos métodos da revisão sistemática, ou a da assistemática, não abrangeria questões primordiais que direcionem com mais objetividade as buscas científicas neste artigo; ocasionariam desvios inapropriados, ou mesmo a perda de trabalhos relevantes.

A RBI tem uma abordagem mais ampla referente às revisões; permite a inclusão de pesquisas experimentais e não-experimentais para um entendimento completo do tema analisado. Ajusta dados da literatura empírica e teórica, além de incorporar um amplo plano de propósitos. Essa vasta amostra gera um panorama consistente e de maior clareza entre os conceitos mais complexos e temas relevantes, na área do design.

O método de pesquisa de revisão integrativa originou-se das necessidades de estudo nas áreas da saúde, na enfermagem, na epidemiologia, por exemplo. A Prática Baseada em Evidências (PBE), a qual tem origem no trabalho do epidemiologista Archie Cochrane, destaca-se por possuir um enfoque voltado ao cuidado clínico e ao ensino fundamentado no conhecimento e na evidência. Tem como tópicos: a definição do problema clínico, a identificação das informações necessárias, a condução da busca de estudos na literatura e sua avaliação crítica, a aplicabilidade dos dados advindos das publicações e a determinação de seu emprego no paciente (SOUZA; SILVA; CARVALHO, 2010). Na área da medicina, por exemplo, a pesquisa tende a ser anedótica, pois trata cada caso numa sucessão de estudos, em que se registra um relato do uso de medicamento específico, o que não necessariamente funcionaria em outro paciente. A medicina baseada em evidências se opõe quase diametralmente a este procedimento. Semelhantemente, no contexto desta problematização de método de revisão bibliográfica, procurase desenvolver métodos que incorporem os resultados de maneira mais precisa e significativa, na busca de soluções para a área do design. 
Projética, Londrina, v. 12, n. 1, p. 39-66, março 2021

Esse método de pesquisa foi adaptado das RBls aplicadas na área de saúde, em caráter experimental. A partir de inúmeros autores e teóricos da revisão, realizaram-se as devidas alterações e encaixes para a área do design de produto, mais especificamente, na pesquisa de tese do doutorado da primeira autora. Consideraram-se os principais temas da pesquisa: processo e desenvolvimento de produto, método da Engenharia Kansei (Metodologia que surgiu no Japão, criada pelo engenheiro de produção e professor da Universidade de Hiroshima, Mitsui Nagamachi, na década de 1970. Por atuar na área de qualidade total no setor industrial, implantou o sistema na produção de vários artefatos, resultando em inúmeros e sofisticados tipos de metodologia.), Color trim [Etapa de desenvolvimento do design de interiores (automóveis, aeronaves) aberta a designers fundamentados e orientados por diversas áreas do conhecimento. 0 profissional de Color \& Trim deve estar sempre atento às tendências de moda, arte, arquitetura, comportamento, tecnologia e inovação.] e Interior de aeronaves.

A aplicação da RBI nesta pesquisa resultou em doze artigos e foram selecionadas dezenove teses para o preparo e estudo inicial do planejamento teórico e metodológico da proposta de tese.

\section{DESENVOLVIMENTO}

A Engenharia Kansei consiste em uma tecnologia que interpreta os sentimentos dos usuários para um parâmetro do design específico. O envolvimento do usuário é fundamental no desenvolvimento de produtos. Se o produto é feito para o usuário, isso significa que o ponto de vista do usuário deve ser compreendido e considerado, para o produto ser desenvolvido e lançado no mercado, evitando erros e prejuízos das empresas fabricantes (NAGAMACHI; LOKMAN, 2011, p. 4).

O desenvolvimento do color trim da cabine do interior de aeronaves ainda segue a produção tradicional do design de interiores, ou seja, as propriedades e características nem sempre são testadas, aplicadas conforme as considerações dos 


\section{Uma revisão bibliográfica integrativa... interior de aeronaves}

LEE, Erika Yamamoto; EL MARGHANI, Viviane Gaspar Ribas

usuários, mas com o que é fornecido pelo mercado fabril das texturas e cores já previamente ofertadas (KONAN; DIAS; KOUYA, 2014). Contudo, algumas indústrias automobilísticas oferecem oportunidades de escolhas para os clientes/usuários, no ato da compra do produto, abrindo possibilidades na escolha dos atributos, como texturas, formas, cores em determinadas propriedades do layout do painel, dos bancos e da cor externa de seus automóveis "customizáveis". Portanto, a proposta desta investigação fundamenta-se na busca inicial dentre os termos e estudos existentes, para que a investigação prove ser inédita e necessária para o mercado produtor e, principalmente, na união entre a indústria e a academia.

\subsection{Objetivo}

De acordo com a exposição, procura-se oferecer subsídios para a aplicação e construção da RBI no cenário do design de produto no interior de aeronaves. Este artigo tem como objetivo principal apresentar as etapas que compõem o método e os aspectos relevantes a serem levados em conta, para a utilização desse recurso metodológico.

Tem como objetivo específico identificar as pesquisas que caracterizam o fenômeno que envolve a Engenharia Kansei nos processos e desenvolvimento do color \& trim no layout da cabine de passageiros, no interior de aeronaves. Como extensão desse propósito, são tarefas desta pesquisa definir as palavras-chave, bases de busca e periódicos iniciais, para contribuir com a RBI. 
Projética, Londrina, v. 12, n. 1, p. 39-66, março 2021

Figura 1 - Mapa da RBI inicial da proposta de Tese.

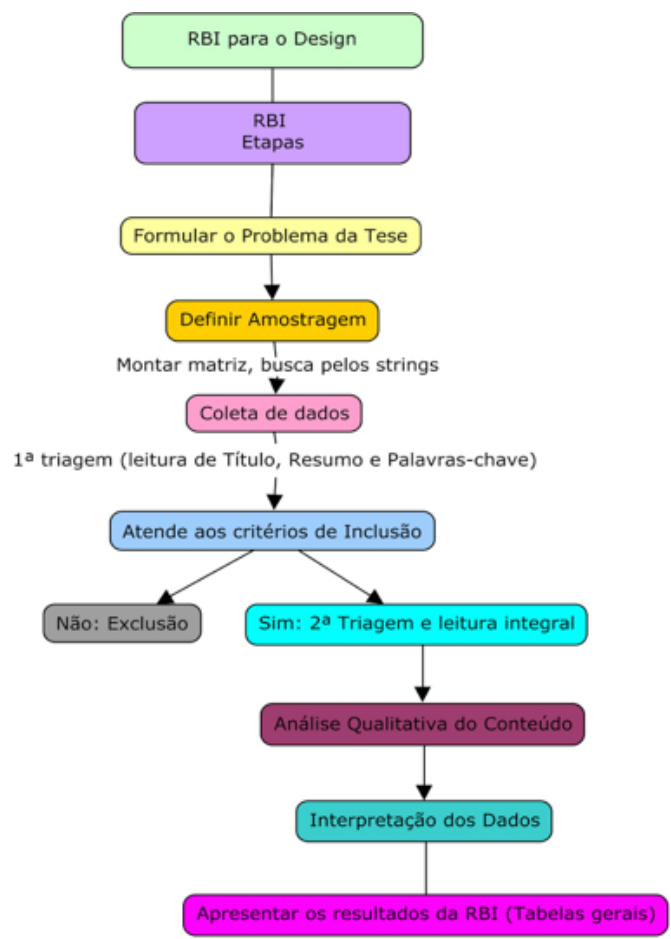

Fonte: Elaborado pela autora.

A RBI tem o propósito de identificar as ferramentas para incluir informações para um exame crítico e detalhar o suficiente para validar os achados. Em suma, deve garantir a visualização e indicar as lacunas dos temas de pesquisa da tese.

O mapa acima (Figura 1) apresenta as etapas realizadas na RBI: a revisão bibliográfica para o design, a formulação das etapas, a definição do problema da revisão, a definição da dimensão de amostragem, a definição os termos, a montagem da matriz, a realização da busca pelos strings (termo inglês usado para combinação de palavras-chave, empregado no método de busca sistemática.) e a coleta dos dados.

Na primeira triagem, foi feita a leitura do título, do resumo e das palavraschave, dentre os artigos e teses encontrados. Após essa seleção, foi implementada 
Uma revisão bibliográfica integrativa... interior de aeronaves

LEE, Erika Yamamoto; EL MARGHANI, Viviane Gaspar Ribas

a segunda triagem dos critérios de inclusão, seguida de uma análise qualitativa do conteúdo, a interpretação dos dados, finalizando-se com os resultados obtidos pela RBI.

\subsection{Métodos}

O estudo é fundamentado com a coleta de dados realizada a partir de fontes secundárias, mediante o levantamento bibliográfico e com base na experiência concretizada pela busca inicial da tese de doutorado em design de produto no setor aeronáutico.

O método de pesquisa da RBI é uma ferramenta de apoio mais eficiente e assertiva que a mais conhecida e utilizada RBS (Revisão Bibliográfica Sistemática), pois, entre os dois métodos sistemáticos, constatou-se que há perdas consideráveis de trabalhos relevantes, durante o percurso da busca. Desse modo, a RBI aplicada tem-se mostrado mais eficaz, por meio das etapas de buscas (COOPER, 1982).

Para o levantamento dos artigos, teses e dissertações, na literatura, efetuou-se a busca nas seguintes bases de dados:

Quadro 1 - Lista das Bases de Dados sobre os temas de pesquisa.

\begin{tabular}{ll}
\hline $\begin{array}{l}\text { Base se Dados Gerais (Artigos e } \\
\text { outras pesquisas em geral) }\end{array}$ & parte específica \\
\hline 1 - Science Direct & 1- Open Thesis \\
\hline 2 - IEEE Xplore Digital Library & 2 - Ethos (UK) \\
\hline 3 - Scielo & 3 - Dart Europe \\
\hline 4 - Emerald & 4 - Virginia Tech \\
\hline 5 - Google Acadêmico & 5 - Dissertation \\
\hline & 6 - Trove \\
\hline 7 - Diva \\
\hline 8 - Biblioteca Digital do ITA \\
\hline 9 - DS Space @ MIT \\
\hline 10 - Georgia Tech \\
\hline
\end{tabular}


Projética, Londrina, v. 12, n. 1, p. 39-66, março 2021

\begin{tabular}{ll}
\hline & 11 - Embry-Ridle \\
\hline 12 - Wichita \\
\hline 13 - Microsoft Academic \\
\hline 14 - Standford University \\
\hline 15 - Cranfield University \\
\hline 16 - Open Access Thesis and \\
Dissertations \\
\hline 17 - Delft \\
\hline 18 - University of Texas \\
\hline 19 - University of Tsukuba \\
\hline 20 - University of Chiba \\
\hline 21 - Banco de teses da CAPES
\end{tabular}

Fonte: Elaborado pela autora.

A revisão bibliográfica é conceituada sobre as questões em cinco etapas paralelas, segundo afirmação do precursor da revisão bibliográfica integrativa (COOPER, 1982).

Para que a revisão seja realizada com a devida consistência, as estratégias metodológicas seguem: unidade de análise, delimitação, critérios para a seleção das amostras, justificativa da escolha estratégica, protocolo de coleta dos dados, análise de dados e, finalmente, métodos estatísticos (gráficos).

\subsection{Unidade de Análise}

Para estudarmos a RBI, efetua-se um quadro comparativo dos métodos de revisão em pesquisa, conforme o método da elaboração: 
Uma revisão bibliográfica integrativa... interior de aeronaves

LEE, Erika Yamamoto; EL MARGHANI, Viviane Gaspar Ribas

Quadro 2 - Quadro comparativo entre as revisões.

\begin{tabular}{|c|c|c|c|c|}
\hline Revisões & Narrativa & Sistemática & Integrativa & Estruturada \\
\hline Objetivo & $\begin{array}{l}\text { Busca } \\
\text { fundamentar } \\
\text { conteúdos } \\
\text { teóricos. }\end{array}$ & $\begin{array}{l}\text { Método de busca } \\
\text { experimental } \\
\text { de recuperação } \\
\text { e análise crítica } \\
\text { da literatura. } \\
\text { Procura } \\
\text { responder a uma } \\
\text { determinada } \\
\text { questão. } \\
\text { (CONFORTO; } \\
\text { AMARAL; SILVA, } \\
\text { 2011) }\end{array}$ & $\begin{array}{l}\text { Método de busca } \\
\text { que permite a } \\
\text { combinação de } \\
\text { dados da literatura } \\
\text { empírica e teórica, } \\
\text { os quais podem } \\
\text { ser direcionados } \\
\text { à definição } \\
\text { de conceitos, } \\
\text { identificação de } \\
\text { lacunas, revisão de } \\
\text { teorias e análise } \\
\text { metodológica dos } \\
\text { estudos dobre } \\
\text { um determinado } \\
\text { tópico. }\end{array}$ & $\begin{array}{l}\text { Inicia-se com } \\
\text { a revisão } \\
\text { exploratória } \\
\text { que mapeia } \\
\text { conceitualmente } \\
\text { o fenômeno. } \\
\text { Identifica as } \\
\text { palavras-chave } \\
\text { e os periódicos } \\
\text { relevantes, antes } \\
\text { da definição do } \\
\text { conteúdo de } \\
\text { pesquisa. }\end{array}$ \\
\hline Processo & $\begin{array}{l}\text { Não esgota } \\
\text { a fonte de } \\
\text { informação. }\end{array}$ & $\begin{array}{l}\text { Testa hipóteses } \\
\text { e tem como } \\
\text { objetivo levantar, } \\
\text { reunir, avaliar } \\
\text { criticamente a } \\
\text { metodologia } \\
\text { da pesquisa e } \\
\text { sintetizar os } \\
\text { resultados de } \\
\text { diversos estudos } \\
\text { primários. }\end{array}$ & $\begin{array}{l}\text { Delineamento } \\
\text { experimental e } \\
\text { não-experimental, } \\
\text { integra os } \\
\text { resultados. Tem } \\
\text { o potencial de } \\
\text { promover os } \\
\text { estudos de revisão } \\
\text { em diversas áreas } \\
\text { do conhecimento, } \\
\text { mantém o rigor } \\
\text { metodológico } \\
\text { das revisões } \\
\text { sistemáticas. }\end{array}$ & $\begin{array}{l}\text { Sistema que } \\
\text { testa hipóteses } \\
\text { no percurso das } \\
\text { buscas e define } \\
\text { a taxonomia } \\
\text { para analisar } \\
\text { ferramentas e } \\
\text { viabilização do } \\
\text { resultado. }\end{array}$ \\
\hline Etapas & $\begin{array}{l}\text { Sujeito a } \\
\text { interpretação } \\
\text { e seleção do } \\
\text { pesquisador. }\end{array}$ & $\begin{array}{l}\text { Entrada - } \\
\text { Levantamento } \\
\text { Processo - Filtros } \\
\text { Saída - } \\
\text { Resultado. }\end{array}$ & 6 etapas & 9 etapas \\
\hline Resultado & Não preciso. & $\begin{array}{l}\text { Preciso, com } \\
\text { ressalvas. }\end{array}$ & Preciso. & Preciso. \\
\hline
\end{tabular}

Fonte: Elaborado pela autora. 
Projética, Londrina, v. 12, n. 1, p. 39-66, março 2021

Para Levy e Ellis (2006), a revisão de literatura da área de educação, por exemplo, manteve-se restrita a apenas três etapas básicas:

a) Entrada de dados e buscas com um exame generalizado;

b) Processamento mediante a análise de conteúdos e síntese; e

c) Saída, apresentando a revisão da literatura.

Essa revisão caracteriza-se como RBS (Revisão Bibliográfica Sistemática), desprezando as análises mais rigorosas da RBI (LEVY; ELLIS, 2006, p. 182). Na RBS, a entrada consiste na busca geral em bancos de dados universais, passando por filtros com os critérios determinados a responder a um problema e seguindo etapas sequenciais, as quais podem excluir trabalhos relevantes sem o retorno randômico pela meta-análise, que é efetivada numa RBI (VOSGERAU; ROMANOWSKI, 2014).

A Revisão Bibliográfica Integrativa (RBI) possui partes validáveis de um processo da criação e da organização do corpo da literatura. Ela tem sido sustentada pelo argumento de alguns padrões de clareza e rigor, assim como pela replicação da pesquisa primária. A revisão integrativa foi testada em dezessete pesquisas em enfermagem e provou ser a mais rigorosa das revisões literárias (GANONG, 1987).

Apresenta-se no quadro abaixo a relação sintética das RBI estudadas pelos autores selecionados:

Quadro 3 - Relação das etapas entre os autores que analisam o método da RBI.

\begin{tabular}{llllll}
\hline ETAPA 1 & ETAPA 2 & ETAPA 3 & ETAPA 4 & ETAPA 5 & ETAPA 6 \\
\hline Formulação & Busca da & Coleta de & Análise de & Interpretação & Apresentação \\
do problema & $\begin{array}{l}\text { Amostragem } \\
\text { Bibliográfica }\end{array}$ & Dados & Dados & dos dados & da RBI \\
& & & &
\end{tabular}


Uma revisão bibliográfica integrativa... interior de aeronaves

LEE, Erika Yamamoto; EL MARGHANI, Viviane Gaspar Ribas

\begin{tabular}{|c|c|c|c|c|c|}
\hline $\begin{array}{l}\text { Determinar } \\
\text { quais os } \\
\text { estudos a ser } \\
\text { identificados }\end{array}$ & $\begin{array}{l}\text { Critérios de } \\
\text { amostragem } \\
\text { são } \\
\text { indicadores } \\
\text { da } \\
\text { confiabilidade } \\
\text { dos } \\
\text { resultados }\end{array}$ & $\begin{array}{l}\text { Assegurar } \\
\text { que a } \\
\text { totalidade } \\
\text { dos dados } \\
\text { seja extraída, } \\
\text { garantir } \\
\text { precisão na } \\
\text { checagem das } \\
\text { informações } \\
\text { e servir como } \\
\text { registro }\end{array}$ & $\begin{array}{l}\text { Demanda } \\
\text { abordagem } \\
\text { organizada } \\
\text { para } \\
\text { ponderar } \\
\text { o rigor e as } \\
\text { características } \\
\text { de cada } \\
\text { estudo. } \\
\text { Nível 1: Meta- } \\
\text { análise; } \\
\text { Nível 2: } \\
\text { Delineamento } \\
\text { experimental; } \\
\text { Nível 3: quase- } \\
\text { experimentais } \\
\text { Nível 4: } \\
\text { Abordagem } \\
\text { qualitativa } \\
\text { Nível 5: } \\
\text { Relatos de } \\
\text { experiência; } \\
\text { Nível 6: } \\
\text { Opiniões de } \\
\text { especialista }\end{array}$ & $\begin{array}{l}\text { Salientar } \\
\text { conclusões e } \\
\text { inferências }\end{array}$ & $\begin{array}{l}\text { Conter } \\
\text { informações } \\
\text { pertinentes e } \\
\text { detalhadas, } \\
\text { baseadas em } \\
\text { metodologias } \\
\text { contextualizadas, } \\
\text { sem omissões } \\
\text { de evidências } \\
\text { relacionadas }\end{array}$ \\
\hline $\begin{array}{l}\text { Definir os } \\
\text { participantes, } \\
\text { as } \\
\text { intervenções } \\
\text { a serem } \\
\text { avaliadas e } \\
\text { os resultados } \\
\text { a serem } \\
\text { mensurados }\end{array}$ & $\begin{array}{l}\text { Incluir todos } \\
\text { os estudos } \\
\text { encontrados, } \\
\text { ou numa } \\
\text { seletiva } \\
\text { randômica }\end{array}$ & $\begin{array}{l}\text { Deve } \\
\text { apresentar } \\
\text { definição } \\
\text { dos sujeitos, } \\
\text { metodologia, } \\
\text { tamanho } \\
\text { da amostra, } \\
\text { mensuração } \\
\text { de variáveis, } \\
\text { método de } \\
\text { análise e } \\
\text { conceitos } \\
\text { base } \\
\text { empregados }\end{array}$ & $\begin{array}{l}\text { Permitir as } \\
\text { evidências } \\
\text { resultantes } \\
\text { sejam } \\
\text { controladas e } \\
\text { randomizada }\end{array}$ & $\begin{array}{l}\text { Comparar } \\
\text { dados } \\
\text { evidenciados, } \\
\text { identificar } \\
\text { lacunas }\end{array}$ & $\begin{array}{l}\text { Toda relação, } \\
\text { conclusão deve } \\
\text { ser consultada } \\
\text { também pela } \\
\text { fonte primária, } \\
\text { para não haver } \\
\text { conclusões } \\
\text { prematuras/ } \\
\text { exclusão de } \\
\text { evidências } \\
\text { pertinentes } \\
\text { durante o } \\
\text { processo }\end{array}$ \\
\hline
\end{tabular}


Projética, Londrina, v. 12, n. 1, p. 39-66, março 2021

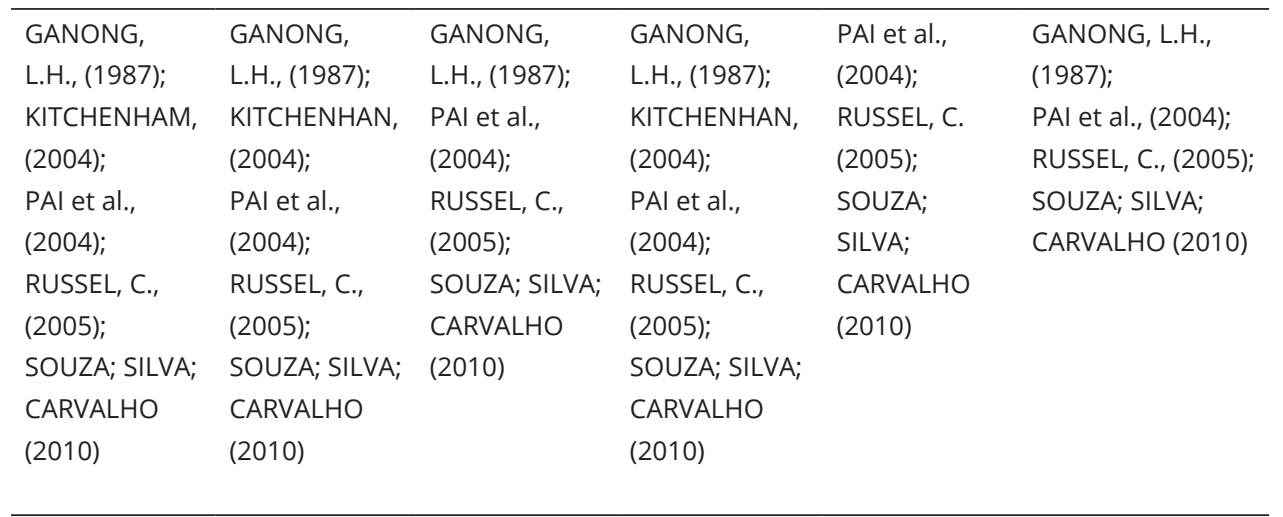

Fonte: Elaborado pela autora.

Deste modo, a Revisão Bibliográfica Integrativa (RBI) é uma abordagem metodológica para as revisões bibliográficas, mais amplas que as demais, pois permite a inclusão de estudos experimentais e não-experimentais para uma compreensão completa do fenômeno que se analisa (SOUZA; SILVA; CARVALHO, 2010).

Para Kitchenham (2004), uma revisão apropriada é a adaptação da revisão integrativa da área de saúde para a ciência de computação, um sistema que valida e interpreta toda pesquisa relevante por uma questão particular, seguindo três etapas:
a) Planejamento da revisão;
b) Condução da revisão;
c) Apresentação do relatório, com foco não apenas no método da pesquisa, mas no conteúdo dos trabalhos, de maneira randômica.

Kitchenham (2004) reforça a importância da terceira etapa, uma vez que na realização da meta-análise dos trabalhos pesquisados é que se encontram conteúdos, temas específicos e autores citados em investigações da área da saúde. 
Uma revisão bibliográfica integrativa... interior de aeronaves LEE, Erika Yamamoto; EL MARGHANI, Viviane Gaspar Ribas

A Revisão Bibliográfica Integrativa (RBI) possui partes vallidáveis de um processo da criação e da organização do corpo da literatura. Ela tem sido sustentada pelo argumento de alguns padrões de clareza e rigor, assim como pela replicação da pesquisa primária. A revisão integrativa foi testada em dezessete pesquisas em enfermagem e provou ser a mais rigorosa das revisões literárias (GANONG, 1987).

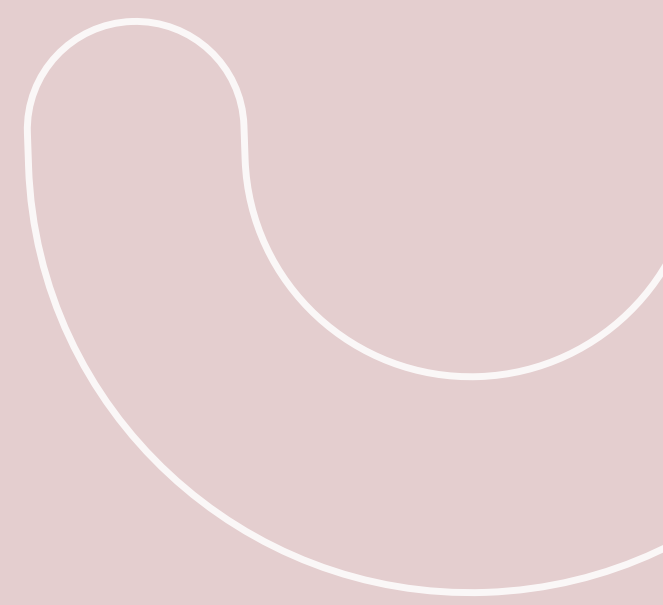


Projética, Londrina, v. 12, n. 1, p. 39-66, março 2021

O autor que mais detalhou o método da RBI, com maior rigor, foi Ganong (1987, p. 2), pois incluiu um exame de relatório que investiga as hipóteses, abre possíveis novas reflexões teóricas competitivas e permite identificar a pesquisa necessária. As normas atribuídas por esse autor, após estudo minucioso, sintetizamse em quatro tópicos fundamentais:

a) Utiliza método para garantir a análise, a precisão e a objetividade;

b) Considera a teoria, o sujeito, o método, o resultado e a variável do estudo;

c) Proporciona ao leitor informação sobre o conteúdo revisado e não enfoca apenas os principais resultados;

d) Informa de maneira objetiva e clara.

Um grupo de pesquisa na área médica, proveniente da Índia (PAI et al., 2004), e o grupo na área da enfermagem paulista (SOUZA; SILVA; CARVALHO, 2010) implementaram o método da RBI em seis etapas:
a) Formulação do problema;
b) Estudo primário das pesquisas bibliográficas, jornais relevantes;
c) Leitura do título, resumo e palavras-chaves;
d) Leitura integral dos artigos selecionados e realização da meta-análise randômica dos artigos;
e) Seleção por critérios estabelecidos;
f) Interpretação e discussão dos resultados.

A realização da meta-análise randômica do passo "d", como eles denominam, reforça a importância da leitura, feita pelo pesquisador, dos conteúdos coletados, a fim de que não se excluam trabalhos relevantes (PAl et al., 2004, p. 88).

Por mais exaustiva que seja a busca dos dados, o enfoque é apresentar o efetivo resultado com maior precisão possível. 


\section{Uma revisão bibliográfica integrativa... interior de aeronaves}

LEE, Erika Yamamoto; EL MARGHANI, Viviane Gaspar Ribas

Os trabalhos de Bento (2012), Crossetti (2012) e Benassi, Amaral e Ferreira (2016) contribuíram no embasamento da formulação da RBI, apresentando também um guia com método sistemático integrativo, o qual incorpora etapas encontradas nos estudos anteriores, entre as áreas da Educação, da Engenharia de Produção e da Enfermagem.

\subsection{Adaptação da RBI para o Design de Produto}

Dentre o estudo e a análise comparativa da revisão integrativa e dos métodos desses autores citados, para o desenvolvimento da RBI nesta pesquisa, foram selecionados: Ganong (1987), Pai et al. (2004), Russel (2005) e Souza; Silva e Carvalho (2010). O critério de seleção foi adequar o método para os interesses específicos na área do design. A fusão do método de cada autor resultou na elaboração de um guia formado por etapas e procedimentos evidenciados no quadro 4.

A RBI buscará, aqui, responder ao seguinte problema formulado: "Como e quais referências bibliográficas abordam e auxiliam os profissionais de projeto, via Engenharia Kansei, a desenvolverem soluções do color e trim para o interior de cabines nas aeronaves?"

Ganong (1987), Pai et al. (2004), Russel (2005) e Souza, Silva e Carvalho (2010) afirmam a necessidade das seis etapas, na revisão:
1) Elaboração da questão (problema) norteadora;
2) Busca ou amostragem na literatura;
3) Coleta de dados;
4) Análise dos dados (meta-análise, se necessário);
5) Interpretação dos dados;
6) Apresentação da RBI.

Desse modo, sintetizou-se o método para o design em seis etapas préestabelecidas. Incluídas no quadro 4 estão as bases de dados gerais e específicas, detalhamentos generalizados e realizados nesta RBI: 
Projética, Londrina, v. 12, n. 1, p. 39-66, março 2021

Quadro 4 - Etapas da RBI.

\begin{tabular}{|c|c|c|c|c|c|}
\hline $\begin{array}{l}1 \text { - Formular o } \\
\text { Problema }\end{array}$ & $\begin{array}{l}2 \text { - Definir } \\
\text { Amostragem }\end{array}$ & $\begin{array}{l}3 \text { - Coletar } \\
\text { Dados }\end{array}$ & $\begin{array}{l}4 \text { - Analisar } \\
\text { os dados }\end{array}$ & $\begin{array}{l}5 \text { - Interpretar os } \\
\text { resultados }\end{array}$ & $\begin{array}{l}6 \text { - } \\
\text { Apresentar } \\
\text { a RBI }\end{array}$ \\
\hline $\begin{array}{l}\text { 1.1 Como } \\
\text { e quais } \\
\text { literaturas } \\
\text { abordam e } \\
\text { auxiliam os } \\
\text { profissionais de } \\
\text { projeto via KE a } \\
\text { desenvolverem } \\
\text { soluções do } \\
\text { color e trim } \\
\text { para o interior } \\
\text { de cabines nas } \\
\text { aeronaves? } \\
\text { (problema da } \\
\text { RBI) }\end{array}$ & $\begin{array}{l}\text { 2.1 Critérios: } \\
\text { 2.1.1 Interpretação } \\
\text { dos resultados } \\
\text { 2.1.2 Detalhamento } \\
\text { do processo } \\
\text { metodológico } \\
\text { 2.1.3 Crítica ao Estado } \\
\text { da arte } \\
\text { 2.1.4 Demonstração } \\
\text { dos resultados } \\
\text { 2.1.5 Citação das } \\
\text { revisões anteriores }\end{array}$ & $\begin{array}{l}3.1 \\
\text { Dimensão de } \\
\text { amostragem } \\
10 \text { materiais } \\
\text { em cada } \\
\text { tópico } \\
\text { (artigos, } \\
\text { teses, } \\
\text { dissertações, } \\
\text { monografias) }\end{array}$ & $\begin{array}{l}\text { 4.1. Redução } \\
\text { dos dados: } \\
\text { utilizar um } \\
\text { sistema de } \\
\text { classificação, } \\
\text { utilizar } \\
\text { técnicas de } \\
\text { redução; } \\
\text { definir } \\
\text { framework; } \\
\text { utilizar por } \\
\text { exemplo } \\
\text { analise de } \\
\text { conteúdo }\end{array}$ & $\begin{array}{l}\text { 5.1 Confrontar os } \\
\text { resultados com } \\
\text { as implicações } \\
\text { primárias; } \\
\text { 5.1.1. comparação } \\
\text { dos dados: } \\
\text { examinar } \\
\text { representações a } \\
\text { fim de identificar } \\
\text { temas, padrões } \\
\text { e relações e } \\
\text { traçar um mapa } \\
\text { conceitual } \\
\text { com essas } \\
\text { informações; }\end{array}$ & $\begin{array}{l}6.1 \text { Incluir } \\
\text { informações } \\
\text { para um } \\
\text { exame } \\
\text { crítico }\end{array}$ \\
\hline $\begin{array}{l}1.2 \text { A revisão } \\
\text { deve buscar } \\
\text { literaturas que } \\
\text { abordem os } \\
\text { temas chaves: } \\
\text { Engenharia } \\
\text { Kansei (KE), } \\
\text { Color e trim, } \\
\text { PDP, Interior } \\
\text { aeronaves e } \\
\text { design. }\end{array}$ & $\begin{array}{l}2.2 \text { montar matriz de } \\
\text { strings }\end{array}$ & $\begin{array}{l}\text { Assegurar } \\
\text { que a } \\
\text { totalidade } \\
\text { dos dados } \\
\text { seja extraída, } \\
\text { garantir } \\
\text { precisão na } \\
\text { checagem } \\
\text { das } \\
\text { informações } \\
\text { e servir como } \\
\text { registro }\end{array}$ & $\begin{array}{l}4.2 . \\
\text { representar } \\
\text { os dados: } \\
\text { utilizar } \\
\text { matrizes, } \\
\text { quadros, } \\
\text { gráficos, } \\
\text { mapas, etc.; }\end{array}$ & $\begin{array}{l}5.2 \text { formular } \\
\text { conclusões e } \\
\text { verificar: esforço } \\
\text { de interpretação } \\
\text { das relações } \\
\text { identificadas para } \\
\text { um grau maior } \\
\text { de abstração, } \\
\text { contrapondo } \\
\text { com a literatura } \\
\text { original a fim de } \\
\text { manter a precisão } \\
\text { e conformidade, } \\
\text { todo o processo } \\
\text { deve ser relatado } \\
\text { de maneira } \\
\text { transparente e } \\
\text { crítica }\end{array}$ & $\begin{array}{l}6.2 \text { Detalhar } \\
\text { o suficiente } \\
\text { para o leitor } \\
\text { validar os } \\
\text { achados }\end{array}$ \\
\hline
\end{tabular}


Uma revisão bibliográfica integrativa... interior de aeronaves

LEE, Erika Yamamoto; EL MARGHANI, Viviane Gaspar Ribas

\begin{tabular}{|c|c|c|}
\hline $\begin{array}{l}1.3 \text { Os critérios } \\
\text { de inclusão: } \\
\text { Estudos que } \\
\text { abordem, } \\
\text { principalmente, } \\
\text { a utilização da } \\
\text { Engenharia } \\
\text { Kansei para } \\
\text { o PDP em } \\
\text { Design. Área de } \\
\text { concentração } \\
\text { no design } \\
\text { produto, } \\
\text { engenharia } \\
\text { mecânica e } \\
\text { engenharia } \\
\text { de produção. } \\
\text { Critérios de } \\
\text { classificação: } \\
\text { Trabalhos que } \\
\text { abordem dois } \\
\text { ou mais dos } \\
\text { temas chave } \\
\text { dentro do } \\
\text { conteúdo da } \\
\text { proposta da } \\
\text { tese }\end{array}$ & $\begin{array}{l}2.3 \text { Strings: Tabelas e } \\
\text { quadros }\end{array}$ & $\begin{array}{l}5.3 \text { Garantir a } \\
\text { visualização das } \\
\text { lacunas } 5.3 .1 \\
\text { Indicar novas } \\
\text { temáticas ou } \\
\text { futuras pesquisas }\end{array}$ \\
\hline $\begin{array}{l}\text { 1.4 Determinar } \\
\text { (detalhar os } \\
\text { subtópicos) } \\
\text { os estudos } \\
\text { sobre grafismo; } \\
\text { forma; color e } \\
\text { trim; }\end{array}$ & $\begin{array}{l}\text { 2.4 Definir as bases } \\
\text { de dados (portais: } \\
\text { Periódicos Capes, IEEE } \\
\text { Xplore Digital Library, } \\
\text { Scopus, Science } \\
\text { Direct, Emerald, } \\
\text { Google academico. } \\
\text { Banco de teses: Open } \\
\text { Thesis, Domínio } \\
\text { público, Ethos } \\
\text { (UK), Dart-europe, } \\
\text { vtechworks.lib, BASE- } \\
\text { search, diva-portal. }\end{array}$ & $\begin{array}{l}5.4 \text { Avaliar o } \\
\text { procedimento } \\
\text { adotada ao longo } \\
\text { do trabalho }\end{array}$ \\
\hline
\end{tabular}

Fonte: Elaborado pela autora. 
Projética, Londrina, v. 12, n. 1, p. 39-66, março 2021

Definida a pergunta central da pesquisa, os temas centrais da revisão serão os norteadores da primeira busca, seguindo critérios pré-estabelecidos, como a utilização da KE (Engenharia Kansei) no desenvolvimento de PDP (Processo e Desenvolvimento de Produto) em Design ou Engenharia de Produção. Definição de áreas de concentração: Design de Produto, Engenharia Mecânica, Engenharia de Produção e Engenharia Aeronáutica.

Selecionar trabalhos que abordem dois ou mais dos temas-chave do conteúdo da proposta de tese.

Ao determinar os temas norteadores, subtópicos serão formados e detalhados, considerando-se, por exemplo, o grafismo, a forma, a cor e o color trim. No tópico do processo de projeto, serão balizadas as etapas equivalentes com as do método Kansei, bem como o processo e desenvolvimento da cabine do passageiro para aeronaves comerciais.

Com o resultado desse primeiro levantamento, definem-se os critérios da amostragem.

\subsection{Amostra}

Nesta etapa de definição de amostragem, segue-se a avaliação da primeira etapa de busca, com os seguintes critérios de seleção:
a) 1 - Interpretam-se os dados coletados;
b) 2 - Detalham-se os processos metodológicos presentes nos trabalhos;
c) 3 - Crítica ao Estado da Arte;
d) 4 - Demonstra-se o resultado;
e) 5 - Verificam-se os nomes e autores citados.

Ao passar pelos critérios estabelecidos, definem-se os termos essenciais para a construção dos strings de busca, na elaboração das matrizes entre os termos definidos. 
A definição dos strings de busca foi feita por meio de uma matriz, como se verifica no exemplo genérico (apenas cinco termos para o esclarecimento do procedimento; une-se a palavra da linha vertical somada à linha horizontal e assim por diante, validando as palavras de cima da linha diagonal em $X$, ou a da linha inferior da fileira de $X)$, a seguir:

Quadro 05 - Matriz para formação dos strings de busca.

\begin{tabular}{|c|c|c|c|c|c|}
\hline Matriz AND & Design & KE & Model & Project & Development \\
\hline Design & $x$ & $\begin{array}{l}\text { Design AND } \\
\mathrm{KE}\end{array}$ & $\begin{array}{l}\text { Design and } \\
\text { Model }\end{array}$ & $\begin{array}{l}\text { Design and } \\
\text { Project }\end{array}$ & $\begin{array}{l}\text { Design and } \\
\text { Development }\end{array}$ \\
\hline KE & $\begin{array}{l}\text { KE and } \\
\text { design }\end{array}$ & $x$ & $\begin{array}{l}\text { KE and } \\
\text { model }\end{array}$ & $\begin{array}{l}\text { ke and } \\
\text { project }\end{array}$ & $\begin{array}{l}\text { ke and } \\
\text { development }\end{array}$ \\
\hline Model & $\begin{array}{l}\text { model and } \\
\text { design }\end{array}$ & model and KE & $x$ & $\begin{array}{l}\text { model and } \\
\text { project }\end{array}$ & $\begin{array}{l}\text { model and } \\
\text { development }\end{array}$ \\
\hline Project & $\begin{array}{l}\text { Project and } \\
\text { design }\end{array}$ & $\begin{array}{l}\text { project and } \\
\mathrm{KE}\end{array}$ & $\begin{array}{l}\text { project and } \\
\text { model }\end{array}$ & $x$ & $\begin{array}{l}\text { project and } \\
\text { development }\end{array}$ \\
\hline Development & $\begin{array}{l}\text { development } \\
\text { and design }\end{array}$ & $\begin{array}{l}\text { development } \\
\text { and KE }\end{array}$ & $\begin{array}{l}\text { development } \\
\text { and model }\end{array}$ & $\begin{array}{l}\text { development } \\
\text { and project }\end{array}$ & $x$ \\
\hline
\end{tabular}

Fonte: Elaborado pela autora.

Com a construção da matriz completa, os strings definidos são: Design, Kansei Engineering, Model, Project, Develoment, Product development, Product design, Process, Industrial Design, Color Trim, Airplane Interior, Airplane Fuselage, Cabin Passenger, Airplane Cabin, Airplane Layout, Cabin Layout, Aircraft Interior, Aircraft Fuselage, Aircraft Cabin e Aircraft Layout - cruzados em strings de busca "AND" e "OR" (uma tabela ou matriz para cada conjunto de palavras). Resultaram quadros de 200 combinações (termos em inglês para as bases estrangeiras). 
Projética, Londrina, v. 12, n. 1, p. 39-66, março 2021

Da segunda triagem da etapa 2, resultaram os termos mais relevantes para a busca da proposta de tese: A relação das palavras traduzidas em português - Desenvolvimento Produto; Campo Característica; Desejo usuário; Sentimento usuário; Engenharia Kansei; Propriedades Produto; Color trim; Interior Aeronave; Cabine passageiro. A partir desse resultado, a coleta de dados foi novamente aplicada e selecionada pelos cinco critérios estabelecidos.

Figura 4 - Gráfico que apresenta as lacunas de pesquisa.

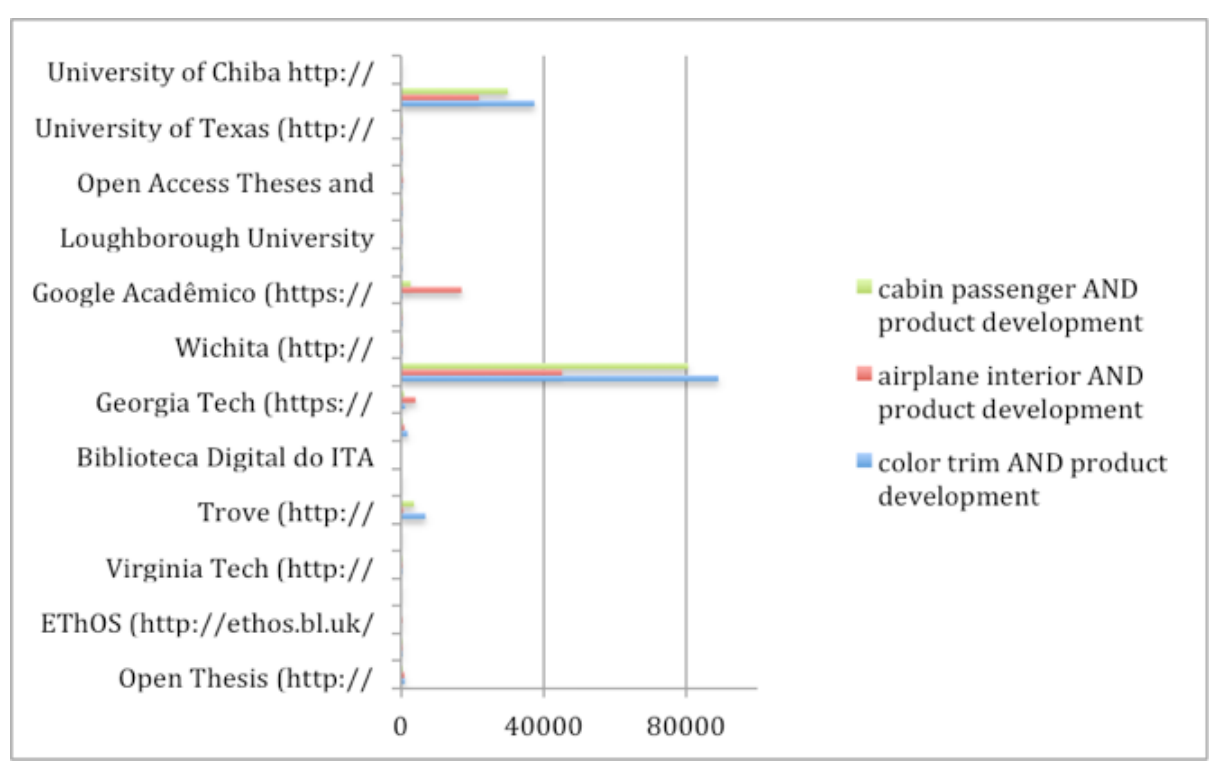

Fonte: Elaborado pela autora.

$\mathrm{Na}$ busca pelas teses específicas, encontraram-se as lacunas da pesquisa entre as vinte e uma bases científicas das principais fontes acadêmicas pelo mundo. Apresentam-se relevantes gráficos que demonstram os resultados da investigação [Etapa 5 (conforme Figura 2): garantir a visualização clara e precisa da lacuna de pesquisa]: 
Figura 3 - Gráfico que apresenta as lacunas de pesquisa.

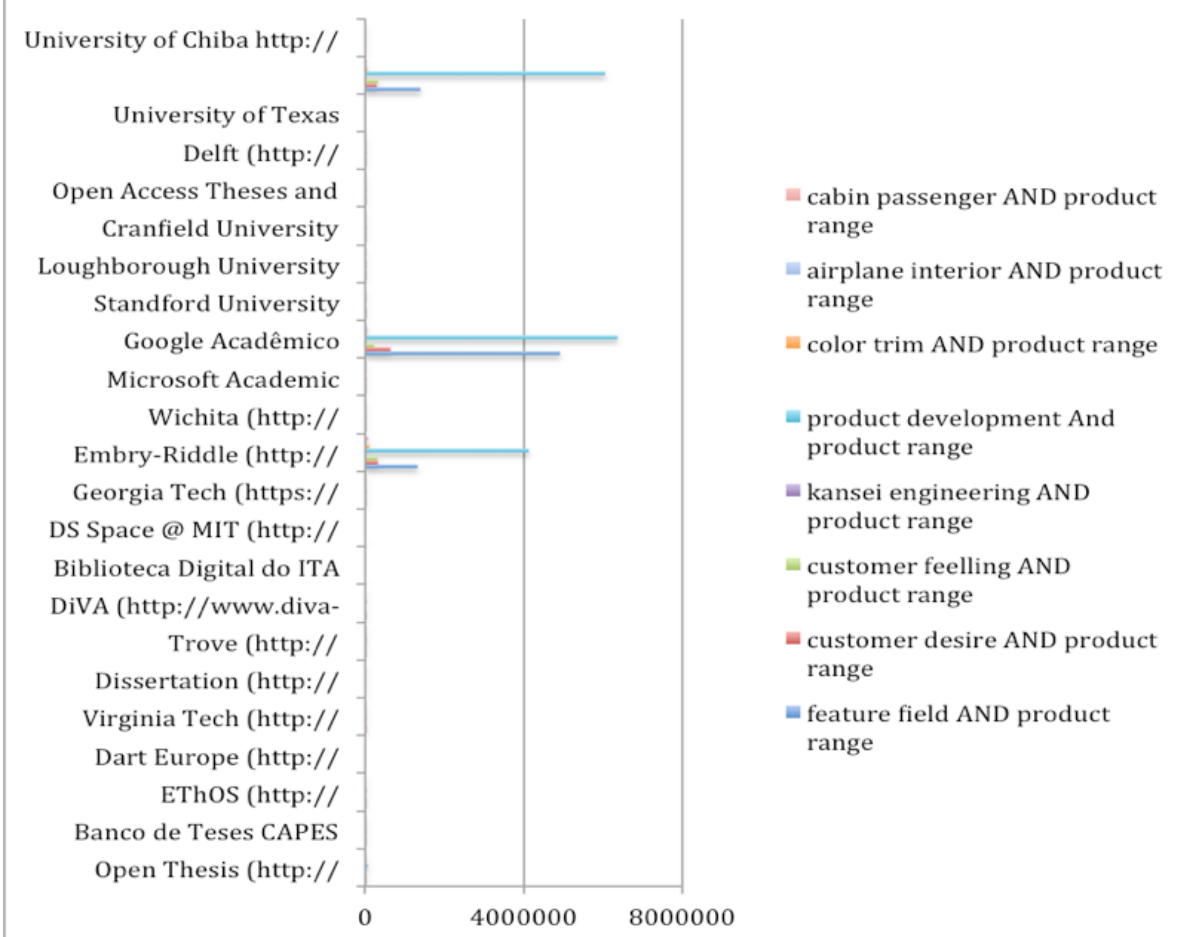

Fonte: Elaborado pela autora.

Nas Figuras 3 e 4, é possível visualizar as lacunas entre os termos cruzados, sendo que a concentração quantitativa de trabalhos remete às bases abrangentes, como a Embry-Riddle e o Google acadêmico.

\subsection{Análise e Interpretação dos Conteúdos}

A etapa 4 da figura norteadora (Figura 2), que corresponde à análise e à interpretação dos conteúdos, foi efetivada de acordo com os seguintes critérios de seleção de trabalhos: na primeira triagem, foram levados em conta os títulos, os 
Projética, Londrina, v. 12, n. 1, p. 39-66, março 2021

resumos e as palavras-chave. Na segunda triagem, os artigos selecionados foram lidos integralmente. Em tal tarefa, foram observados os seguintes nove critérios:
a) Concordância com a pesquisa;
b) Abordagem do problema;
c) Metodologia dos processos do conteúdo de interesse;
d) Estado da Arte;
e) Citação da revisão anterior;
f) Critérios para inclusão do estudo;
g) Amostragem do método;
h) Declaração do propósito; e
i) Demonstração dos resultados.

Assim, as etapas 5 e 6 (cf. Figura 2) seguem a segunda triagem, na qual foram encontrados e identificados 18 artigos e 15 teses, dentro do propósito da pesquisa, diretamente pelas bases de dados. Na terceira triagem (análise do conteúdo completo), foram selecionados 11 artigos e 7 teses. Os autores que explicitam o enquadramento dos critérios se apresentam a seguir:

Quadro 6 - Lista de Autores dos artigos e teses selecionados.

\begin{tabular}{|c|c|c|c|c|c|}
\hline \multicolumn{6}{|c|}{ Referências obtidas na $2^{a}$ Triagem } \\
\hline Artigos & & & ses & & \\
\hline K.E. & Color trim & $\begin{array}{l}\text { Interior } \\
\text { Aeronaves }\end{array}$ & K.E. & Color trim & $\begin{array}{l}\text { Interior } \\
\text { Aeronaves }\end{array}$ \\
\hline $\begin{array}{l}\text { Okamoto (2016) } \\
\text { Brito (2015) }\end{array}$ & $\begin{array}{l}\text { Xiong (2016) } \\
\text { Imaizumi } \\
(2015)\end{array}$ & $\begin{array}{l}\text { Ciaccia \& } \\
\text { Sznelwer } \\
(2016)\end{array}$ & $\begin{array}{l}\text { Tanure (2015) } \\
\text { Verri (2015) } \\
\text { Nunes (2015) }\end{array}$ & $\begin{array}{l}\text { Raine } \\
\text { (2008) }\end{array}$ & $\begin{array}{l}\text { Negroni } \\
(2012)\end{array}$ \\
\hline $\begin{array}{l}\text { Verri (2014) } \\
\text { Nunes (2014) }\end{array}$ & Azhar (2015) & $\begin{array}{l}\text { Konan, Dias e } \\
\text { Kouya (2014 }\end{array}$ & $\begin{array}{l}\text { Razza (2014) } \\
\text { Gabardo } \\
(2014)\end{array}$ & $\begin{array}{l}\text { Dutton } \\
(2006)\end{array}$ & $\begin{array}{l}\text { Suarez } \\
(2009\end{array}$ \\
\hline $\begin{array}{l}\text { Levi (2013) } \\
\text { Carreira (2012) }\end{array}$ & $\begin{array}{l}\text { Dengkhai } \\
(2005)\end{array}$ & Barros (2011) & Xiao (2013) & $\begin{array}{l}\text { Glotzbach } \\
(2004)\end{array}$ & $\begin{array}{l}\text { Azano } \\
(2005\end{array}$ \\
\hline $\begin{array}{l}\text { El Marghani } \\
(2011,2012)\end{array}$ & $\begin{array}{l}\text { Horiuchi } \\
(2004)\end{array}$ & $\begin{array}{l}\text { Eelman } \\
(2004)\end{array}$ & $\begin{array}{l}\text { Kagiyama } \\
(2011)\end{array}$ & & $\begin{array}{l}\text { Santos } \\
(2004)\end{array}$ \\
\hline
\end{tabular}


Uma revisão bibliográfica integrativa... interior de aeronaves

LEE, Erika Yamamoto; EL MARGHANI, Viviane Gaspar Ribas

Referências obtidas na $2^{\mathrm{a}}$ Triagem

Nagamachi (2011) Tenneti (2007)

Fonte: Elaborado pela autora.

Autores constantes e citados em outras buscas: El Marghani, Verri, Nagamachi, para o tema da Engenharia Kansei. Os trabalhos dos demais temas foram selecionados após leitura integral e análise de conteúdo, conforme os nove itens dos critérios de inclusão estabelecidos. A $5^{\text {a }}$ etapa, a qual corresponde à interpretação e à avaliação dos dados, levou em conta os objetivos dos artigos e das teses. Resultaram em 5 artigos e 3 teses/dissertações para o tema Engenharia Kansei; 3 artigos e 3 teses/dissertações para color trim; 3 artigos e 3 teses/ dissertações para interior de aeronaves. O Quadro 2 apresenta essa seleção, em ordem do tema e da data (recente) de publicação:

Quadro 7 - Lista de Autores dos artigos e teses selecionados pela análise dos conteúdos.

\begin{tabular}{|c|c|c|c|c|c|c|}
\hline \multirow[t]{2}{*}{ Temas } & \multicolumn{2}{|l|}{$\begin{array}{l}\text { Engenharia } \\
\text { Kansei }\end{array}$} & \multicolumn{2}{|l|}{$\begin{array}{l}\text { Color } \\
\text { trim }\end{array}$} & \multicolumn{2}{|l|}{$\begin{array}{l}\text { Interior } \\
\text { Aeronaves }\end{array}$} \\
\hline & Artigos & Teses & Artigos & Teses & Artigos & Teses \\
\hline \multirow[t]{5}{*}{$\begin{array}{l}\text { Autores/ } \\
\text { Ano }\end{array}$} & $\begin{array}{l}\text { Okamoto } \\
(2016)\end{array}$ & $\begin{array}{l}\text { Tanuri } \\
\text { (2015) }\end{array}$ & $\begin{array}{l}\text { Xiong } \\
(2016)\end{array}$ & $\begin{array}{l}\text { Glotzbauch } \\
\text { (2004) }\end{array}$ & Ciaccia (2016) & $\begin{array}{l}\text { Negroni } \\
\text { (2012) }\end{array}$ \\
\hline & Verri (2014) & $\begin{array}{l}\text { Verri } \\
(2015)\end{array}$ & $\begin{array}{l}\text { Azhar } \\
(2015)\end{array}$ & & $\begin{array}{l}\text { Konan, Dias e } \\
\text { Kouya (2014) }\end{array}$ & $\begin{array}{l}\text { Asano } \\
(2005)\end{array}$ \\
\hline & $\begin{array}{l}\text { Carreira } \\
(2012)\end{array}$ & $\begin{array}{l}\text { Xiaoying } \\
(2013\end{array}$ & $\begin{array}{l}\text { Horiuchi } \\
\text { (2004) }\end{array}$ & & Barros (2011) & $\begin{array}{l}\text { Santos } \\
(2004)\end{array}$ \\
\hline & $\begin{array}{l}\text { El Marghani } \\
(2012)\end{array}$ & & & & & \\
\hline & $\begin{array}{l}\text { Nagamachi } \\
\text { (2011) }\end{array}$ & & & & & \\
\hline
\end{tabular}

Fonte: Elaborado pela autora. 
Projética, Londrina, v. 12, n. 1, p. 39-66, março 2021

\section{CONCLUSÃO}

A revisão bibliográfica integrativa determina o conhecimento atual sobre o(s) tema(s) específico(s). No resultado, foram selecionados doze artigos e dezenove teses, com base nos critérios estabelecidos, os quais contribuem na resolução do problema formulado. As etapas foram conduzidas de maneira a identificar, analisar e sintetizar o resultado da pesquisa.

Destaca-se a quarta etapa da RBI, porque analisa os dados encontrados e retorna a análise de trabalhos relevantes. Assim, essa meta-análise soma e repercute na qualidade e na acuidade da investigação. Para refletir sobre o método da revisão bibliográfica, enfoca-se o impacto da utilização da RBI, tanto no desenvolvimento do protocolo quanto no procedimento de pesquisa do pensamento crítico da prática de revisão bibliográfica. O protocolo desenvolvido, o qual foi adaptado para as necessidades do Design, foi aplicado conforme os critérios capazes de resultar nos trabalhos que apresentassem as investigações já existentes e que também contribuíssem no construto da proposta de pesquisa.

Figura 5 - A lacuna entre os temas pesquisados.

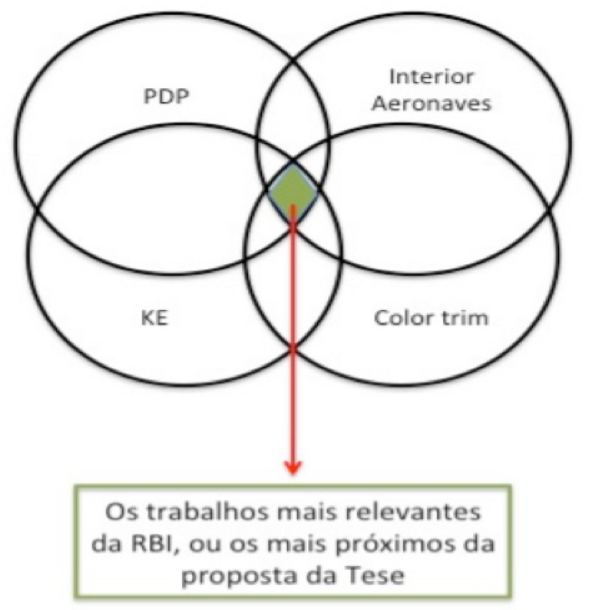

Fonte: Elaborado pela autora. 


\section{Uma revisão bibliográfica integrativa... interior de aeronaves}

LEE, Erika Yamamoto; EL MARGHANI, Viviane Gaspar Ribas

Em face dessa necessidade de garantir uma execução baseada em evidências científicas, a RBI tem sido indicada como uma ferramenta eficaz, pois explicita, nos resultados de pesquisa, o direcionamento fundamentado em base científica. Essa revisão mostrou condução eficiente, porque combina os dados e delimita a investigação, diminuindo as perdas duma revisão sequencial sistemática e encontrando a lacuna de pesquisa com maior assertividade. Portanto, é essencial firmar a RBI como instrumento válido na pesquisa em design, principalmente no campo aeronáutico, onde é exigida a atribuição máxima de precisão e segurança ao usuário. 
Projética, Londrina, v. 12, n. 1, p.39-66, março 2021

\section{REFERÊNCIAS}

1. BENASSI, João Luís Guilherme; AMARAL, Daniel Capaldo; FERREIRA, Lucelindo Dias. Towards a conceptual framework for product vision. Journal of Operations \& Production Management, Bingley, UK, v. 36, n. 2, p. 200-219, 2016. Disponível em: http://www.emeraldinsight.com/doi/pdfplus/10.1108/ IJOPM-11-2013-0511.

2. BENTO, António V. Como fazer uma revisão da literatura: considerações teóricas e práticas. Revista JA (Associação Académica da Universidade da Madeira), Funchal, PT, v. 7, n. 65, p. 42-44, 2012. Disponível em: http://www3. uma.pt/bento/Repositorio/Revisaodaliteratura.pdf.

3. CONFORTO, Edivandro Carlos; AMARAL, Daniel Capaldo; SILVA, Sérgio L. Roteiro para revisão bibliográfica sistemática: aplicação no desenvolvimento de produtos e gerenciamento de projetos. In: CONGRESSO BRASILEIRO DE GESTÃO DE DESENVOLVIMENTO DE PRODUTO - CBGDP, 8., 2011, Porto Alegre, RS. Anais [...]. Porto Alegre: UFRGS, 2011. p. 1-12.

4. COOPER, Harris. Scientific guidelines for conducting integrative literature reviews. Review of Educational Research, Washington, DC, v. 52, n. 2, p. 291-

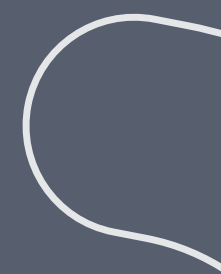
302, 1982. http://rer.sagepub.com/content/52/2/291.abstract.

5. CROSSETI, Maria da Graça Oliveira. Revisão integrativa de pesquisa na enfermagem o rigor científico que Ihe é exigido. Revista Gaúcha de Enfermagem, Porto Alegre, RS, v. 33, n. 2, p. 8-9, 2012. http://www.scielo.br/ pdf/rgenf/v33n2/01.pdf.
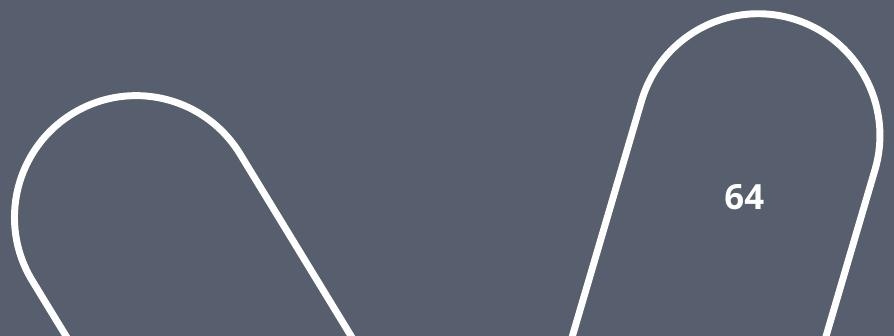
Uma revisão bibliográfica integrativa... interior de aeronaves LEE, Erika Yamamoto; EL MARGHANI, Viviane Gaspar Ribas

6. GANONG, L.H. Integrative reviews of nursing research. Research in Nursing \& Health, New York, v. 10, n.11, p. 1-11. 1987.

7. KITCHENHAM, Barbara Ann. Procedures for performing systematic reviews. Keele University Technical Report, Staffordshire, UK, v. 1, n. 1, p. 1-33, 2004. http://people.ucalgary.ca/ medlibr/kitchenham_2004.pdf.

8. KONAN, Akpaulai Timothée Bezalel; DIAS, Cleidson Nogueira; KOUYA, Firmin Freid. Critérios de seleção de fornecedores em produtos da indústria aeronáutica: o caso dos e-jets da EMBRAER. In: SIMPÓSIO DEADMINISTRAÇÃO DA PRODUÇÃO, LOGÍSTICA E OPERAÇÕES INTERNACIONAIS - SIMPOI, 17. 2014, São Paulo, SP. Anais [...]. São Paulo: FGVSP, 2014. p. 1-17.

9. LEVY, Yair; ELLIS, Timothy J. A systems approach to conduct an effective literature review in support of information systems research. Informing Science Journal, Bethesda, MD, v. 9, n. 9, p. 181-212, 2006. http://inform.nu/ Articles/Vol9/V9p181-212Levy99.pdf.

10. NAGAMACHI, Mitsuo. Kansei/ affetive engineering and history of Kansei engineering in the world. In: NAGAMACHI, Mitsuo (ed.). Kansei/ affective engineering. 3. ed. London: Taylor \& Francis, 2011. p. 1-13.

11. NAGAMACHI, Mitsuo; LOKMAN, Anitawati Mohd. Innovations of kansei engineering. 3. ed. London: Taylor \& Francis, 2011.

12. PAI, Madhukar; MCCULLOCH, Michael; GORMAN, Jennifer D.; PAI, Nitika; ENANORIA, Wayne; KENNEDY, Gail, THARYAN, Prathap; COLFORD JUNIOR, John M. Systematic reviews and meta-analyses: an illustrated, step-by-step

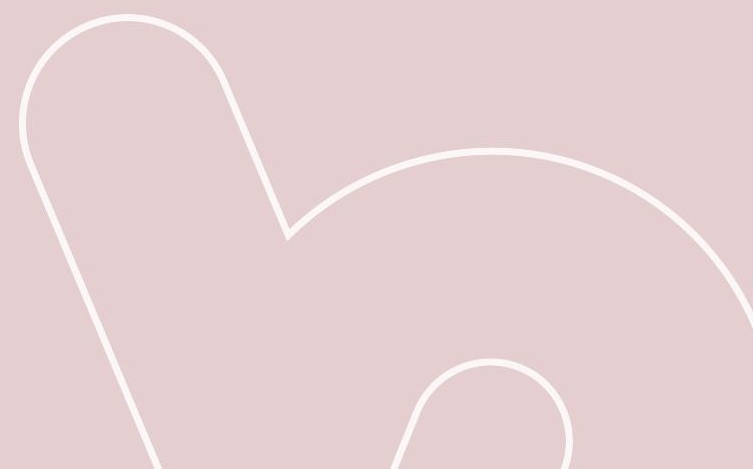


Projética, Londrina, v. 12, n. 1, p.39-66, março 2021

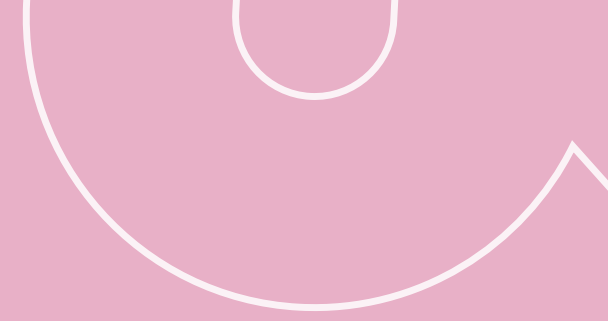

guide. The National Medical Journal of India, New Delhi, v. 17, n. 2, p. 86-95, 2004. http://www.ncbi.nlm.nih.gov/pubmed/15141602.

13. RUSSEL, I. Cynthia. Evaluating quantitative research reports In Nephrology nursing journal: journal of the American Nephrology Nurses' Association 32(1):61-4. PubMed. Janeiro 2005.

14. SOUZA, Marcela Tavares de; SILVA, Michelly Dias da; CARVALHO, Rachel de. Revisão integrativa: o que é e como fazer. Revista Einstein, São Paulo, SP, v. 8 , n. 1, p. 1-5, 2010. http://www.scielo.br/pdf/eins/v8n1/pt_1679-4508eins-8-1-0102.pdf. Acesso em: 2 jul. 201.

15. VOSGERAU, Dilmeire Sant'Anna Ramos; ROMANOWSKI, Joana Paulin. Estudos de revisão: implicações conceituais e metodológicas. Revista Diálogo Educacional, Curitiba, PR, v. 14, n. 41, p. 165-189, 2014. http://www2.pucpr. br/reol/pb/index.php/dialogo?dd1=12623\&dd99=view\&dd98=pb. 